\title{
A statistical analysis of achievement in self-study summer books
}

\author{
PLÁCIDO BAZO \\ Universidad de La Laguna \\ Marcos Peñate and Patricia Arnaiz \\ Universidad de Las Palmas de Gran Canaria \\ Hazel Geatches \\ Oxford University Press
}

Received: 15 september 2006 / Accepted: 22 october 2006

ISSN: $1697-7467$

\begin{abstract}
In this article we present all the results obtained from our research based on the use of self-study books. In a previous report we outlined the way pupils and parents used the holiday books, whereas in this article we will focus our attention on the evaluation of the activities done by the students during their summer holidays. We will, in particular, analyse the results obtained by pupils from state and private schools, by boys and girls and by second and third cycle pupils.
\end{abstract}

Key words: English as a foreign language, self-study summer books, primary education, statistical analysis.

RESUMEN: En el presente artículo exponemos todos los resultados obtenidos en una investigación que tuvo como objetivo estudiar el uso de los cuadernos de verano de inglés en primaria. En un informe publicado anteriormente presentamos el uso dado a estos cuadernos de vacaciones por los alumnos y padres, pero ahora vamos a prestar especial atención a los resultados obtenidos al evaluar las actividades realizadas. En particular, comparamos estadísticamente los resultados obtenidos por el alumnado de colegios públicos y privados, por los chicos y las chicas, y por el alumnado del segundo y tercer ciclo de primaria.

Palabras clave: Inglés lengua extranjera, cuadernos de vacaciones, educación primaria, análisis estadístico

\section{INTRODUCTION}

The use of self-study books during the summer has been an important tool in the Spanish educational system during the last 20 years. The tradition stretches for a long period of time and covers most of the subjects in the curriculum of Primary and Secondary Education. Parents, teachers and publishing companies have promoted the use of these products during the Spanish long summer vacations with the basic idea of not only entertaining the pupils 
but with the purpose of recycling the basics of what has been learned or acquired during the previous course.

The English summer books have developed during the last decade with many of the major publishing companies devoting time and resources to the creation of these materials. The teacher trainers in the Faculties of Education and the Ministry of Education have pressed so that this material contains two basic components: a) the construction of elements that could evolve into the autonomous learning of a foreign language and b) the introduction of the strategies needed to work in isolation and without the help or guidance of a teacher.

As J. L.Vera (2000) points out it is difficult to make students aware of their autonomy in terms of their responsibility. This is certainly true of the Spanish context where students and pupils expect the teacher to feed them with knowledge, even at university level.

An important characteristic of autonomous foreign language learners is that they can identify their own needs, strengths and weaknesses and they can set appropriate goals accordingly. These learners have to develop what Breen and Mann (1997) refer to as the robust sense of self and a strategic engagement with learning. This is a very complicated process that must be initiated in the classroom and must continue outside it. One has to bare in mind that classroom-based learners are often under pressure to master a pre-determined set of linguistic, attitudinal and strategic objectives and the principal reflection comes from the teachers.

According to H. Holec (1981) learner autonomy is when the learner is willing and capable of taking charge of his or her learning. In other words, the learners should be capable of determining the objectives, defining the contents and the progressions, selecting methods and techniques to be used, monitoring the procedure of acquisition and evaluating what has been acquired. A decade later, D. Little (1991) insisted in that, essentially, autonomy must be seen as the capacity for detachment, critical reflection, decision making and independent action. It presupposes, but also entails, that the learner will develop a particular kind of psychological relation to the process and content of learning. These two authors assume that the learner is a reflective person and that capacity has been forced to be developed in Spain with the 1992 Education Act (known popularly as LOGSE). The results so far are unknown but progress seems to have been made.

Obviously, autonomy has to be introduced slowly. Pupils and students who want to be autonomous have to be trained to be so and self-study books can play an important role in the whole process. In Spain, several attempts have been made to implement autonomous learning. Especially in the Canary Islands, J. L. Vera (2000) has designed a system using phases and degrees. A phase is defined as a unit of time. It also means a change in any of the curriculum elements. Teachers and students decide to start a new phase according to the evolution of the course and it can affect content, methodology or any other part of the curriculum The system includes four phases: Phase 0 (introduction), Phase I (beginning of programme), Phase II (development) and Phase III (conclusion/end of process). A degree is defined as the intensity of the interdependent relation established between the teacher and the student in parallel to the tasks worked. The system uses the following scale: degree 0 and 1 (the teacher develops tasks which are totally controlled or quite controlled); degree 2 (the teacher controls the task partially); degree 3 (the task is completely or almost completely free from teacher control).

Teacher trainers in Spain insist that the self-study summer books play a role in the development of autonomy because children work without teachers, who traditionally interfere 
in the development of autonomy. Nevertheless, teachers seem not to be so conscious of that and think of the summer books as good basic linguistic content to be remembered.

The second important feature is the relation between this kind of supplementary material and the strategies involved in the acquisition and learning of a foreign language. As Cohen (1998) points out, technically, learning a second language means that the language learned is spoken in the community, while the foreign language is not spoken in the local community. This distinction is very important because, regarding strategies, most research has been done in a second language situation. The learning strategies that interest in the self-study books in the Spanish context are related to the foreign language situation.

Learning strategies have been defined in different ways (Oxford, 1990; Cohen, 1995) but they all coincide that they are learning processes which are consciously selected by the learner. The element of choice is important because this gives a strategy its special character. The strategies are also moves of which learners are at least partially aware of, even if full attention is not given to them. The link between notion and strategy is very important because it implies its implementation during the teaching process and its logical practise then and during the summer with the self-study books. In other words, language learning strategies are the conscious thoughts and behaviours used by learners in order to improve the learning strategy and understanding of the target language. They include cognitive strategies for memorizing and manipulating target language structures, metacognitive strategies for managing and supervising their strategy use, affective strategies for dealing with emotional reactions to learning and social strategies for enhancing learning through the interaction with others.

Language use strategies come into play once the language is already accessible, even in some preliminary form. They focus primarily on helping students use the language they have already stored and they include strategies for retrieving information from language already learned, strategies for rehearsing target language structures and strategies for communicating in the language despite gaps in target language knowledge.

Definitely, language learning and language use strategies can be defined as those processes which are consciously selected by learners and may result in action to enhance the learning or the use of a foreign language trough the storage, retention, recall and application of information about the language. Three months during the summer seem to be a too long period of time for the Spanish Primary and Secondary Education pupils and students not to be in contact with the English language if we have in mind what we just have said about the strategies.

In the last decades, many researchers (see Tarone and Yule, 1989 or Oxford and Leaver, 1996) have recognised the value of explicit instruction in the development, application and transfer of learning strategies The context given by the summer books where most of the time learners seek the help of equals or parents gives an interesting opportunity to complete the strategic training given along the previous course.

Curriculum design has changed into more learner-centred approaches (Wenden, 2002). It has influenced research in second language acquisition and given chances to more research in the field of self-study books. It is known that for many years research on self-study books has been remarkably little (Jones, 1993) although attempts to address the relationship between solo language learning and achievement have been made (Jones, 1998).

On the other hand, foreign language theory and research has been investigating the relationship between acquisition and communication and the relationship with instruction, 
input and output. Little has been researched on the self-study processes. The aim of this paper is to collaborate in the mapping of this neglected area.

\section{RESEARCH DESIGN}

The present study continues the line of research on this field, specifically on the use of self-study books. It has been done with pupils, parents and teachers in Primary schools in three Spanish cities: Barcelona, Seville and Bilbao.

\subsection{Objectives}

The present study aims to continue the line of research developed in the introduction of this article and try to fill one of the gaps we have previously mentioned. We are referring to the lack of research about how students do their self-study activities and which specific problems they encounter. In short, our study attempted to reach the following two objectives:

- To check if the pupils studied really did the activities of the holiday books and establish how successful they were.

- To find out the level of satisfaction of pupils, parents and teachers.

Three research questions arose from these objectives:

1. Do pupils really do correctly all the activities of the holiday books without any difficulties?

2. Are there any statistical differences between the results obtained by state and private schools, by boys and girls or by 8-10 year-old pupils (second cycle) and 10-12 yearold pupils (third cycle)?

3. What do parents, teachers and pupils think about the holiday books?

\subsection{Subjects}

The population of our study was made up of the pupils, teachers and parents of seven schools of three Spanish cities: Barcelona, Seville and Bilbao. Out of the seven chosen schools, three were private and four state schools. The reason why we chose four state schools and only three private schools was based on the need to have similar amounts of pupils belonging to both types of schools, as the chosen private schools had more students than the state ones. In the same way, we also tried to have a population with a well-balanced distribution of boys and girls, and also according to the four primary levels to be studied.

Specifically, the subjects who took part in the research were 240 Spanish-speaking pupils, 169 parents and 9 teachers. These final amounts were determined by the number of pupils who did the summer books and handed them in to be checked, and also by the number of parents who volunteered to answer the questionnaires taken home by the pupils. As for the teachers, the ones who took part were those who, of their own free will, accepted the invitation to take part in this research. In fact the willingness of the teachers was the first condition to choose a school in particular. 
The way the 240 pupils are divided into groups belonging to a specific city or type of school is shown in table 1 .

Table 1. Distribution of the pupils according to school and city.

Tabla de contingencia City * School

Recuento
\begin{tabular}{|ll|r|r|r|}
\hline \multirow{2}{*}{} & \multicolumn{2}{|c|}{ School } & \multicolumn{1}{c|}{} \\
\cline { 3 - 4 } & \multicolumn{2}{|c|}{ private } & state & \multicolumn{1}{c|}{ Total } \\
\hline City & Barcelona & 49 & 28 & 77 \\
& Sevilla & 49 & 16 & 65 \\
& Bilbao & 43 & 55 & 98 \\
Total & & 141 & 99 & 240 \\
\hline
\end{tabular}

In this first table, it can be seen that the number of private school pupils is about a fifty per cent bigger than the number of state school pupils. That is, it can be said that this is the first result obtained from our study: though we had chosen similar populations, the number of subjects of private schools is significantly bigger, which indicates that private school children have a bigger readiness to do the holiday books. Though, in some cases, we also found that private school children were obliged to do the summer books by their teachers or by their parents. As an example, one parent wrote in the questionnaire: "My son finished the book because he didn't have a choice, not because he liked it."

Another piece of information that could be of interest is the way the 240 pupils are distributed according to their level (from $3^{\text {rd }}$ to $6^{\text {th }}$ primary year) and whether they are boys or girls. All this can be seen in table 2 .

Table 2. Distribution of the pupils according to sex and level.

Tabla de contingencia Level * Sex

\begin{tabular}{|c|c|c|c|c|c|}
\hline \multicolumn{5}{|c|}{ Sex } & \multirow[b]{2}{*}{ Total } \\
\hline & & female & male & unknown & \\
\hline \multirow[t]{4}{*}{ Level } & level 3 & 36 & 30 & & 66 \\
\hline & level 4 & 29 & 38 & & 67 \\
\hline & level 5 & 24 & 29 & 9 & 62 \\
\hline & level 6 & 24 & 18 & 3 & 45 \\
\hline Total & & 113 & 115 & 12 & 240 \\
\hline
\end{tabular}

Here we are faced with a distribution that attracts our attention due to their similarity: 115 boys and 113 girls. There are also 12 kids who didn't specify their names on their books so it couldn't be established whether they were boys or girls. This so well-balanced distribution seems surprising because we expected to get a bigger number of girls than boys, as traditionally girls are considered to be more receptive to this type of task. 
As for the distribution per level, there are amounts between 60 and 70 pupils for the first three levels and a rather smaller amount for the last one (45 pupils of level 6). Nevertheless, we can't hazard a guess based on this data as it turned out to be quite difficult to locate the pupils studying year 6 in state schools after the summer holidays, as they began their secondary studies in a different school.

\subsection{Instruments}

The development of the three research questions obliged us to get data from different sources and use the following tools to obtain the information required. We had to create questionnaires so that the pupils, parents and teachers could provide us with the needed information. Another important tool used was the pupils' books which were borrowed for three months to carry out their analysis.

\subsubsection{The questionnaires}

For the writing of the questionnaires for pupils, parents and teachers, we followed parallel and simultaneous processes. We elaborated a specification table which included the dimensions we wanted to study: accomplishment, difficulty, enjoyment, help, correction, and usefulness. At the time of stating the specific aspects for each dimension, we decided to write them as questions that would be used in the questionnaires. Finally we specified the source from which we wanted to get the information required (parents, teachers or pupils).

Table 3. Specification table used for the writing of the questionnaires.

\begin{tabular}{|l|l|l|}
\hline Dimensions & Specific aspects & Source \\
\hline Accomplishment & - Did your son/daughter finish all units? & Parents \\
\hline Difficulty & $\begin{array}{l}\text { How difficult the book was: } \\
\text { - The level of Holiday English is high / right / } \\
\text { low }\end{array}$ & Teachers \\
\cline { 2 - 3 } & $\begin{array}{l}\text { How difficult the activities were: } \\
\text { - Did your son/daughter have problems with } \\
\text { the activities? } \\
\text { - The activities were very difficult / difficult / } \\
\text { normal / easy } \\
\text { - The activities were difficult / right / easy }\end{array}$ & Parents \\
\hline Enjoyment & $\begin{array}{l}\text { - Did your son/daughter like the book? } \\
\text { - Were the activities entertaining or boring? } \\
\text { - Did you like the design? }\end{array}$ & $\begin{array}{l}\text { Peachers } \\
\text { Pupils } \\
\text { Pupils }\end{array}$ \\
\hline Help & $\begin{array}{l}\text { - Did you have to help your son/daughter? } \\
\text { - Were the instructions helpful? } \\
\text { - Was the support given (vocabulary lists, } \\
\text { grammar files, etc.) helpful? }\end{array}$ & $\begin{array}{l}\text { Parents } \\
\text { Pupils }\end{array}$ \\
\hline - Who corrected the activities? & Pupils \\
\hline Correction & $\begin{array}{l}\text { - Why did you recommend Holiday English? } \\
\text { - Do you think it helps students improve their } \\
\text { English? }\end{array}$ & $\begin{array}{l}\text { Teachers } \\
\text { Teachers }\end{array}$ \\
\hline Usefulness & & \\
\hline
\end{tabular}


Obviously all the questionnaires had to be written using the mother tongue to guarantee that, specially, parents and pupils could understand the questions and express their opinions without any problems.

\subsubsection{The holiday activity books}

The books we use for our research are called Holiday English (Oxford University Press). These are a 4-level DIY holiday activity books to be completed in the summer holidays by primary school children. Levels 3 and 4 are for 8-10 year-old and levels 5 and 6 for 10-12 year-olds. When they do levels 5 and 6 , children are in the latter stages of primary.

These books are based on the opinion that children of this age group will only settle to do a page of the holiday book for 20-30 minutes at a time. Therefore the material is attackable in small chunks of time, with very clear contextualization via artwork and instant recognition of what the exercise requires you to do. Other important features which have been implemented are: a visual attractiveness, an interesting content, humour and fun puzzles.

As for the books, we labelled all of them so that each one could be identified and referred to individually, and also by city and by school. We created a spreadsheet for each level, and inputted an answer code for each child's answers to all the activities.

\section{RESUltS AND DISCUSSION}

The presentation of the results obtained and their discussion will be done divided into three sections, in accordance with the three research questions stated at the beginning of this article.

\subsection{Level of accomplishment and difficulties}

The main purpose of our first research question was to find out whether the students really do all the activities in the holiday books or not. But also we intended to pinpoint any difficulties they might encounter when doing the activities by themselves away from the classroom and the teacher's help.

To give an answer to the first part of the first research question we used the information obtained by means of the analysis and correction of the books and also from the parents' questionnaires. We considered it to be important to check whether each pupil has done the activities or nor, but also we thought it was worthwhile to know the evaluation provided by the parents about their children's performance.

The level of accomplishment of the pupils was studied following two steps. First it was studied whether the pupil had finished the book or not and, later on, each activity was checked to see if it had been done and if there were any significant errors.

For the overall information, we used the parent's questionnaire. The answers given by the parents concerning whether their son or daughter had or nor finished all units are included in figure 1. 
Figure 1. Level of accomplishment according to the opinion given by parents

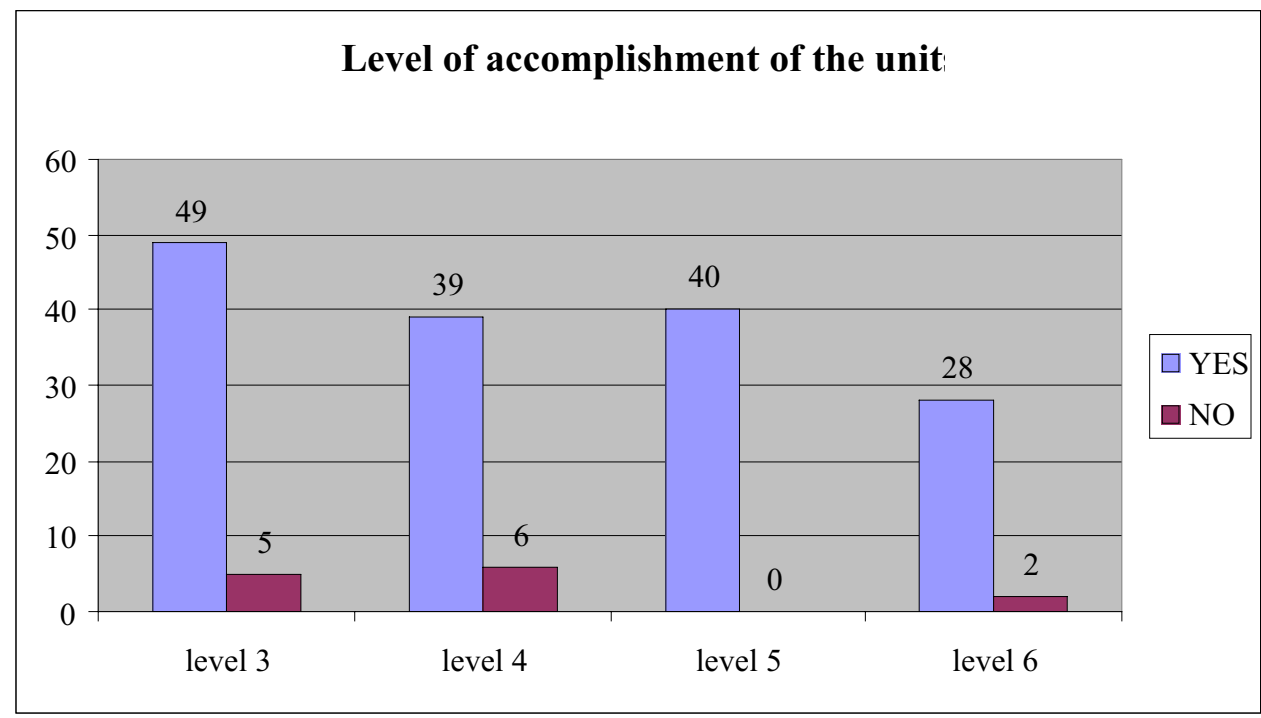

In this figure we can see, first and foremost, the way the 169 parents are distributed in the four levels studied. It can be seen that the number decreases as the age of the pupils rises.

As can be seen by the answers given by parents, most children seem to have finished all the units in the book. And of the 13 who didn't finish their books, 6 finished almost all units, 1 half the book, 1 three units, 1 only did one and 4 didn't answer how many their children did.

Apart from that, we were also interested in knowing how difficult the book was. To assess this we used the information provided by the teacher's questionnaire. The nine teachers who took part in our research filled in a questionnaire for each of the levels they taught. This is the reason why we have a total of 24 questionnaires distributed as follows: seven for level 3 , five for level 4 and six for each of the last two levels.

Teachers were asked to establish if the level of Holiday English was high, right or low. In this particular case, we have found a unanimous assessment since all of them considered the level to be the right one.

Once we had the information needed about the book as a whole and specifically about the degree of accomplishment, we began a thoroughly study of each book to find out whether each pupil had done each activity or not. For the assessment of each activity we used the following book marking: 3 for perfect, 2 for almost perfect, 1 for activity with significant errors and 0 for activities which were not attempted by the children. Later on, each activity was assigned to one of the following types: listening, reading, writing, presentation or practice activities. Whereas the first three types are quite obvious, perhaps we need to clarify what we mean by the last two ones. In each unit there are always straightforward presentation activities in which the language is presented in quite a simple way. In the same way, there 
are other activities which only intend to practice the language and cannot be considered listening, reading or writing activities. Such is the case of the crosswords for example.

With the scores obtained for each activity, once they were brought together according to the different types of activities, we could work out the percentage of correct answers as can be seen in the following graph.

Figure 2. Average scores obtained by pupils in the different types of activities.

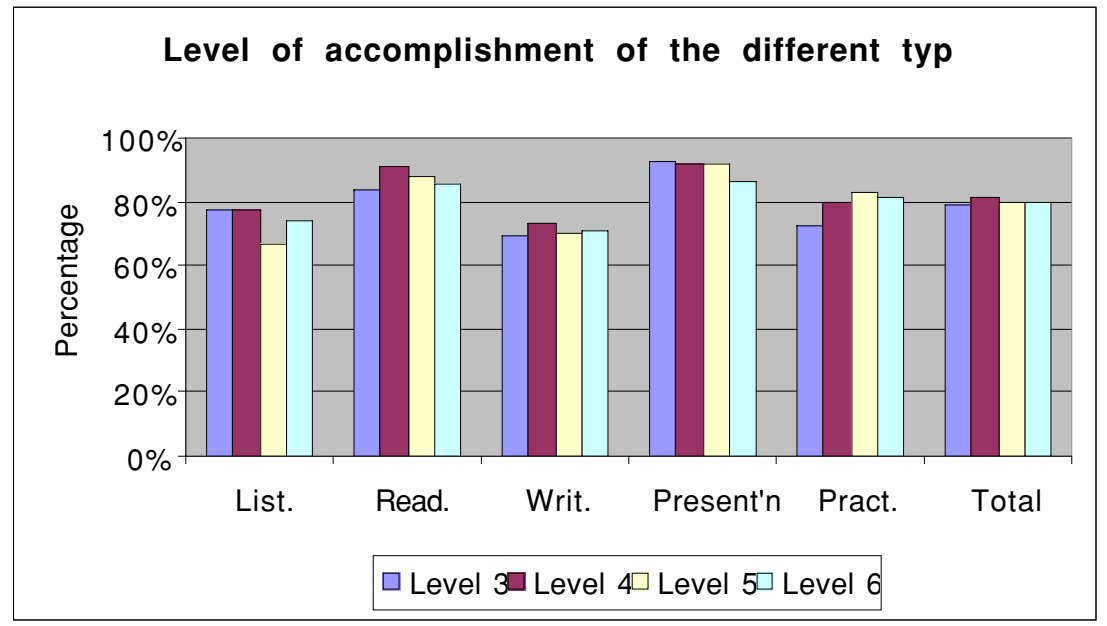

The first characteristic that stands out is the high percentage of activities which were successfully done by the pupils: the average of the total amounts is of 80 per cent. This mean average allows us to divide the activities into two groups, depending on whether they are below or above that mean average. The writing, listening and practice activities are below this mean average (71, 74 and 79 respectively). On the other side we find the presentation activities $(91 \%)$ and the reading activities $(87 \%)$.

As it has happened in other evaluation studies carried out in Spain (Peñate, 1998; Alabau, 2002, Bazo et al. 2003) the writing activities are the ones with lowest scores. Nevertheless in some of these and other studies, as the one by Vez and Martínez (2002), the listening activities frequently appear with correct answer rates higher than the mean. Finally, the practice activities required the writing of words (e.g. crosswords) or completing sentences which increased the possibilities of making mistakes. And this was not the case with the reading activities (multiple choice, true-false questions, etc.) or with the presentation activities where children only had to label pictures with the words provided in boxes.

We have been able to get a clear picture of the degree of accomplishment reached thanks to the data obtained from the correction of each activity of each book of the 240 pupils subjects of our study. But we were also interested in knowing what was the opinion of pupils, parents and teachers about the level of difficulty of the activities.

We will begin by presenting the data obtained from the questionnaires to parents and pupils. We asked the following question to the parents: Did your son/daughter have problems 
with the activities? (Many problems / Quite a few problems / Few problems / No problems). And to the pupils: The activities were ... very difficult / difficult / normal / easy.

Figure 3. Level of difficulty of the activities according to parents and pupils.

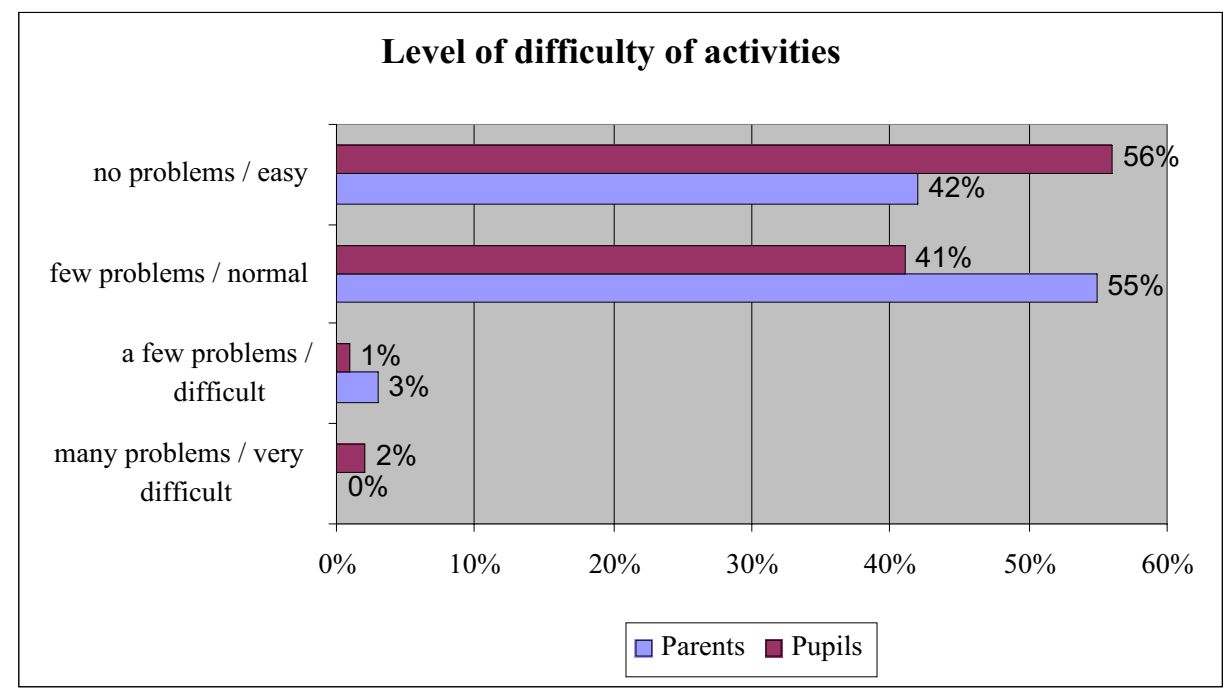

The first characteristic that emerge from the analysis of the results is the clear coincidence between the opinion stated by parents and pupils when evaluating the level of difficulty of the activities, though the pupils seem to favour the option of lower level of difficulty. Another important feature is that only the 3 per cent of parents say that their children had many or quite a few problems. This percentage is exactly the same as the one of pupils who found the activities difficult or very difficult.

Besides the opinions of parents and pupils, we also obtained the opinion of teachers about the level of difficulty of the activities. They were requested to choose among three options: difficult, right or easy. Again, their opinion, as it happened when they assessed the level of difficulty of the books, was unanimous. All their questionnaires state that the activities for each of the four levels have the right level of difficulty.

\subsection{Statistical comparison of means}

Our second research question expected to find out if there were significant differences between the results obtained by the state and private school pupils, by the boys and girls, and by 8-10 year-old pupils (second cycle) y 10-12 year-old pupils (third cycle).

\subsubsection{Sate versus private school pupils}

The scores obtained by pupils belonging to state and private schools are presented in the graph in figure 4. 
Figure 4. Mean scores for each type of activity

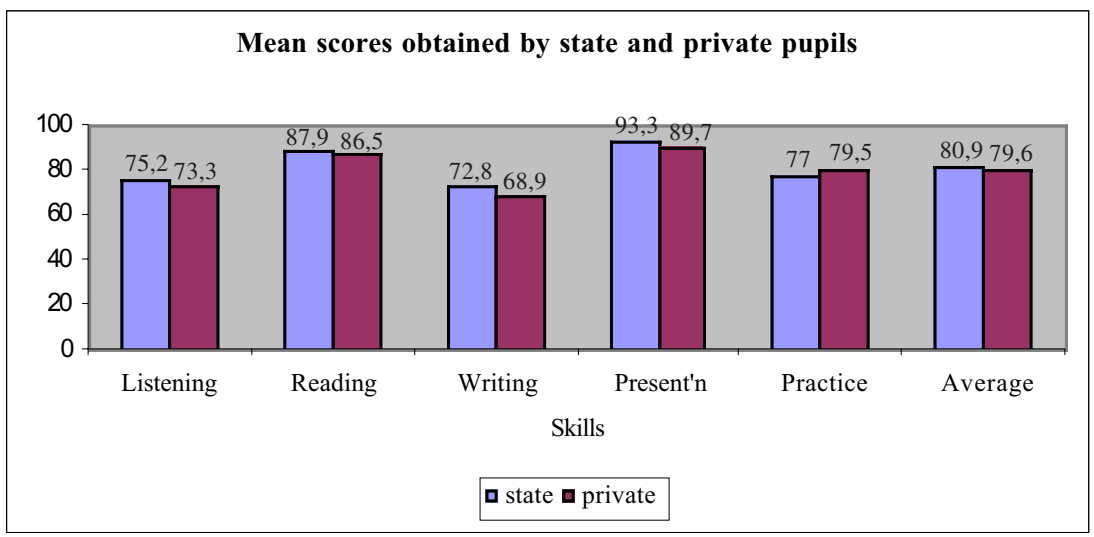

We can see in figure 4 that in practically all types of activities the mean reached by pupils belonging to state schools is higher than the one reached by those belonging to private schools, except in the practice activities where just the opposite happens. Nevertheless, we can see that the mean scores obtained by both groups of pupils are quite similar. It is therefore necessary to compare both means statistically to see if there are significant differences between both means.

The group of children from the state schools scored an average of 80.90 , with a standard deviation of 11.422 , whilst the group from private schools obtained an average of 79.69 , with a standard deviation of 14.326 .

Statistical analysis carried out on these results allowed us to corroborate whether or not there were significant differences between the results obtained. But since we were comparing two independent groups in each case, first we had to study if the groups compared had equal variances. Levene's test for equality of variances was applied. The value obtained for the Levene test was 1.922 , with a probability of 0.167 . Since the probability is higher than 0.05 , it implies that equal variances are assumed.

With the results obtained from the correction of the books, and by means of an independent sample t-test (SPSS 11.0 for Windows), it was possible to establish that there were no significant differences between the scores obtained by the two groups of state and private school children, as can be seen in table 4 .

Table 4. Scores obtained by state and private schoolchildren.

\begin{tabular}{|c|c|c|c|}
\hline Variable & Cases & Mean score & $\begin{array}{l}\text { Standard } \\
\text { deviation }\end{array}$ \\
\hline State schools & 99 & 80.90 & 11.422 \\
\hline Private schools & 141 & 79.69 & 14.326 \\
\hline T value & \multicolumn{2}{|c|}{ Degrees of freedom } & Probability \\
\hline 0.699 & \multicolumn{2}{|l|}{238} & 0.485 \\
\hline
\end{tabular}


As can be seen, the probability is higher than 0.05 , which leads to the conclusion that there were no significant differences between the scores obtained by the state and private school pupils of our study.

\subsubsection{Male versus female school pupils}

The scores obtained by the boys and girls are presented in the graph in figure 5 .

Figure 5. Mean scores for each type of activity

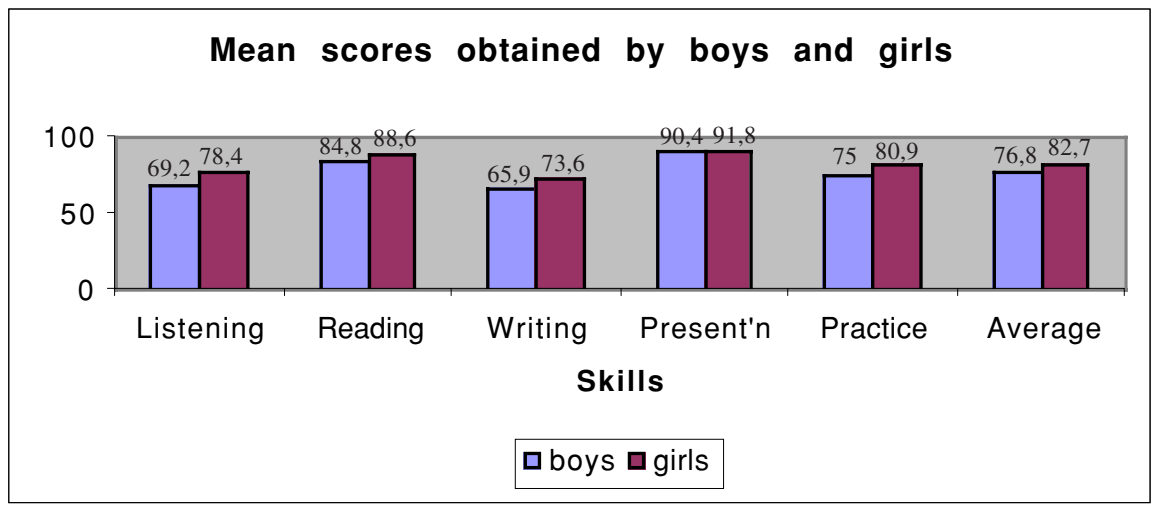

In this particular case, there is a constant tendency in all the scores obtained for each type of activity, as in all of them the means obtained by girls are higher than the ones obtained by boys. If we arrange them according to the differences observed beginning by the one with the biggest difference, we would get the following order: listening, writing, practice, reading and presentation activities. Whereas in the presentation activities the difference hardly exceeds one point, we can see that in the listening activities it is almost of ten points. These data allow us to predict that possibly there will be significant differences between the means obtained by each group.

The group of schoolboys scored an average of 76.83, with a -standard deviation of 13.603, whilst the group of schoolgirls obtained an average of 82.72 , with a standard deviation of 12.439 .

Statistical analysis carried out on these results allowed us to corroborate whether or not there were significant differences between the results obtained. Again we had to study if the groups compared had equal variances. The value obtained for the Levene test was 0.824 , with a probability of 0.365 . Since the probability is higher than 0.05 , it implies that equal variances are assumed.

With the results obtained from the checking of the activities, and by means of an independent sample t-test, it was possible to establish that there were significant differences between the scores obtained by the two groups of male and female school children, as can be seen in table 5 . 
Table 5. Scores obtained by the male and female schoolchildren

\begin{tabular}{llll}
\hline Variable & Cases & Mean score & $\begin{array}{l}\text { Standard } \\
\text { deviation }\end{array}$ \\
\hline Second cycle & 133 & 80.02 & 12.739 \\
Third cycle & 107 & 80.40 & 13.796 \\
T value & Degrees of freedom & Probability \\
-0.225 & 238 & 0.822 \\
\hline
\end{tabular}

As can be seen, the probability is lower than 0.05, which leads to the conclusion that there were significant differences between the scores obtained by the boys and girls of our study.

There were also significant differences between the scores obtained for each subskill except for the presentation activities where the probability obtained is higher than 0.05 (0.232).

\subsubsection{Second versus third cycle}

Of the 240 pupils, 133 were in the second cycle and 107 in the third, which represents a $55.4 \%$ and a $44.6 \%$ respectively. The scores obtained by the pupils in each cycle are presented in figure 6 .

Figure 6. Mean scores for each type of activity

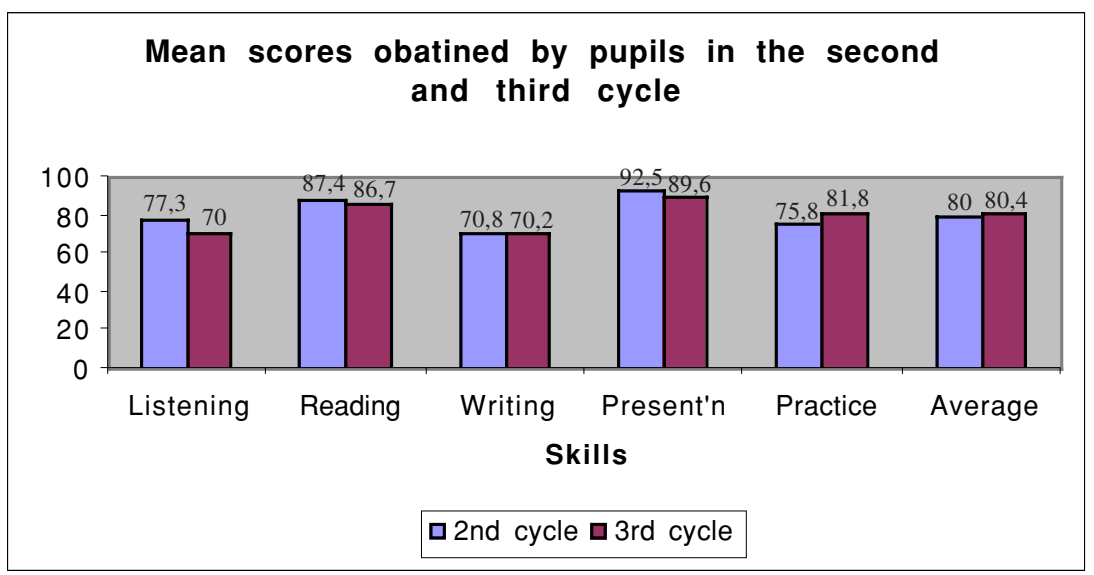

We can see in figure 6 that in practically all types of activities the mean reached by pupils of the second cycle is higher than the one reached by those in the third cycle, except in the practice activities where just the opposite happens. It can also be seen that the average score is almost the same which allows us to anticipate that there will not be significant differences between both groups. 
The second cycle pupils scored an average of 80.02, with a standard deviation of 12.739 , whilst the third cycle pupils obtained an average of 80.40 , with a standard deviation of 13.796.

Table 5. Scores obtained by the male and female schoolchildren.

\begin{tabular}{|c|c|c|c|}
\hline Variable & Cases & Mean score & $\begin{array}{l}\text { Standard } \\
\text { deviation }\end{array}$ \\
\hline Second cycle & 133 & 80.02 & 12.739 \\
\hline Third cycle & 107 & 80.40 & 13.796 \\
\hline T value & \multicolumn{2}{|c|}{ Degrees of freedom } & Probability \\
\hline-0.225 & \multicolumn{2}{|l|}{238} & 0.822 \\
\hline
\end{tabular}

Once it was established, with the Levene test, that equal variances were assumed, we proceeded to compare the scores with the independent sample t-test once more. The results obtained, which can be seen in table 5, clearly show that there are not significant differences between the scores obtained by the two groups of pupils as the probability is higher than 0.05 .

\subsection{Feedback from parents, pupils and teachers}

The last of our research questions was aimed at getting information concerning four dimensions we had included in the questionnaires to parents, pupils and teachers. We are referring to the following ones: enjoyment, help, correction and usefulness.

The main purpose of the first dimension (enjoyment) was to find out if the pupils enjoyed themselves doing the activities in the books during their summer holidays, as it is considered to be an important motivation factor (Madrid, 1999:99). To reach this goal, three questions were used. The first one directed to the parents (Did your son/daughter like the book?) and the other two ones to the pupils (Were the activities entertaining or boring? and Did you like the design?).

The answers given by parents and pupils to the first two questions have been summarized in the next figure.

Figure 7. Level of enjoyment according to parents and pupils.

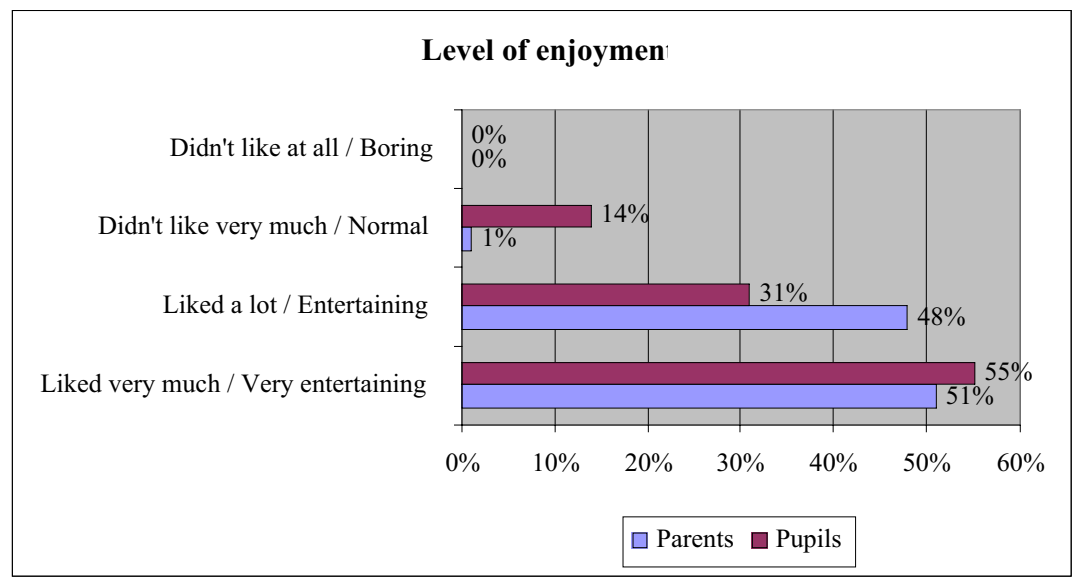


The first piece of information worthwhile mentioning is that not even one parent or pupil stated that he or she disliked or found boring the activities presented in the books. Nevertheless the positive opinion was more marked in the parents than in the pupils, as while the $99 \%$ of parents think that their children liked the books very much or a lot, the total amount of children who found the activities entertaining or very entertaining is slightly smaller $(86 \%)$.

As for the opinion about the design given to the activities, 192 pupils, out of the 214 who completed the questionnaire, thought that it was attractive or very attractive; whereas 21 found it not very attractive and only one considered it to be unattractive.

The second aspect which was studied, inside this last research question, was the one about the degree of help given by parents, by instructions in the mother tongue and by the rest of support given (vocabulary lists and grammar files). By means of one question in the parent's questionnaire and two in the pupil's questionnaire we obtained the information summarized in table 6 .

Table 6. The degree of help given to the pupils

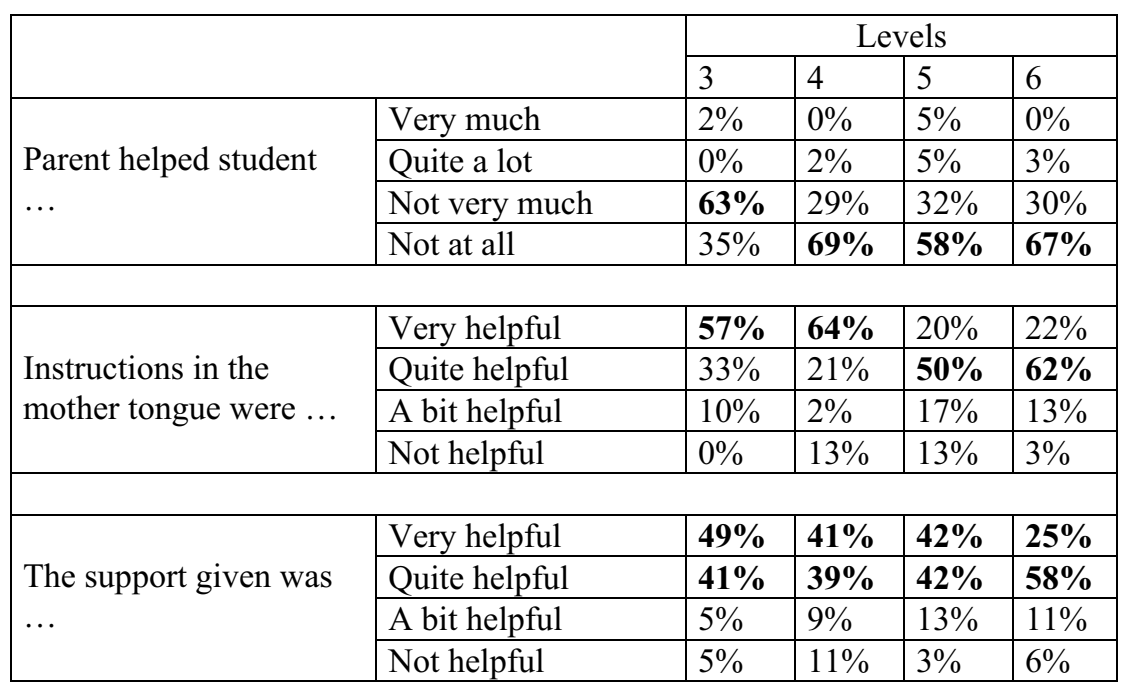

It can be seen in the above table that the amount of help given by parents was very little. The only level where there was a little bit of help was in level 3, to the youngest children. In the other levels the highest percentage always belongs to the option "Not at all". There may be different reasons for this lack of help provided by parents. One of them, as many parents wrote in the space provided for comments in the questionnaires, is that they didn't help as many of them couldn't speak English. And some of those who did help also pointed out that rather than help, they have been a guide or an orientation. Another possible reason is that this help was not needed as the instructions in the mother tongue, together with the example provided in each activity guided the pupils and so they could finish the activities really quickly. 
We have just mentioned the possible positive role played by the instructions and this was precisely one of the questions the pupils had to answer. These instructions in the mother tongue were considered to be very helpful for most of the pupils in the first two levels and quite helpful for the eldest ones. And the support given by means of vocabulary lists (English - mother tongue) and grammar files (simple straightforward explanations of grammar points adapted to this age group) turned out to be quite helpful or very helpful for the eighty per cent or more of the pupils.

But parents also were expected to decide who was going to correct the activities, using the pull out key provided with each book. To get this information the parents were asked a multiple choice question: Who corrected the activities? The five options provided were: student, student with another student, student with an adult, adult, nobody corrected.

When reading the options chosen by parents we could first notice that for levels 4,5 and 6 , the most frequently chosen option was the first one, that is, the pupils correct the activities by themselves. The only exception was for the youngest children where the most frequent situation was the one where the pupils correct the activities with the help of an adult. However, when we consider all the data for the four levels, as it appears in figure 8, we can't fail to see the important role played by parents (only in same rare cases the adult was a private teacher or an older brother or sister) at the time of correcting the activities. In the 60 per cent of cases it was done by the parents with or without the pupil. This piece of information seems to contradict something which has been mentioned above: many parents couldn't help their children because they don't speak English. Nevertheless they have been able to correct the activities, in spite of their lack of knowledge of the English language, as the key to the activities only required to compare the answer provided with the one written by the pupil.

Figure 8. Correction of the activities according to parents' opinion

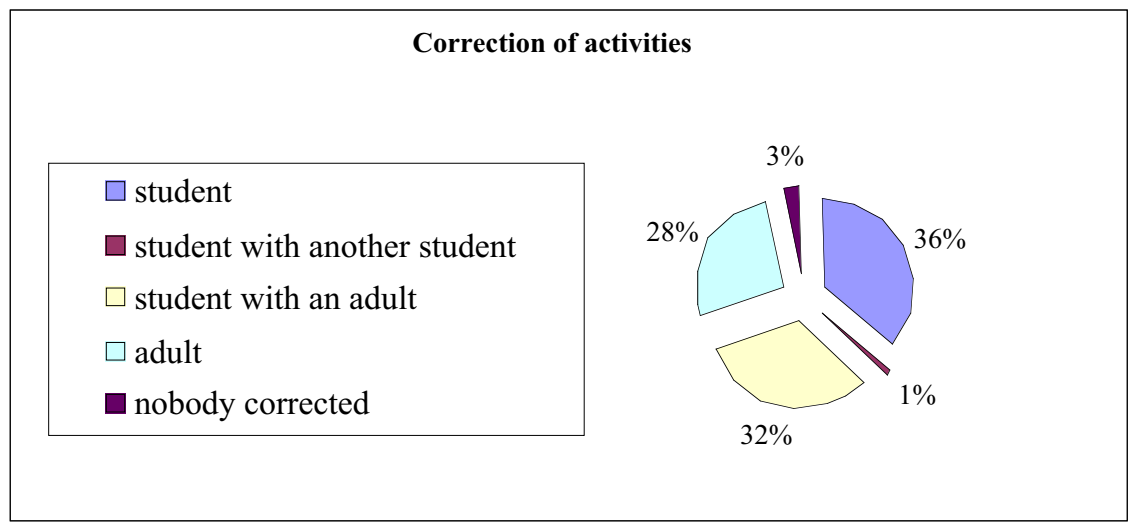

Now that we have so far studied how much the pupils have enjoyed doing the activities, the level of help they have had and who was responsible for the correction of the activities, the time has come for us to find out whether doing this summer books has been useful or not. 
Two questions were asked to the teachers. The first one wanted to know the reason why they had recommended the summer books, whereas the second one tried to find out if those expectations have been fulfilled.

Since the first question (Why did you recommend Holiday English?) was open ended, we will try to summarize the opinions given by the teachers. The first reason for recommending the books was that "the contents are right and according to what had been studied during the course" and "activities are similar and go very well with the material used during the year." And this is an essential requirement "so that the pupils don't forget the vocabulary and grammar, as it is difficult for them to revise this by themselves" and, at the same time, "it gives slow learners / low level children the opportunity to catch up during the summer and start the new course with less problems."

The second question intended to know whether the summer books really helped students improve their English or no. Again all the teachers confirmed that the time spent doing these activities was quite positive for different reasons. It had helped students to refresh their knowledge during the summer and, specially, to review and not to forget English already learnt during the course, consolidating the skills learned. But it also "maintains interest in English during the holidays" and children "get more confidence." In short, the teachers interviewed agree that students come back from their holidays with their English fresh.

\section{Conclusion}

Most children finished all the units in the books and the reason could be summarized in a comment made by some parents: "My child finished the book really quickly. It was the first summer holiday homework done." This probably occurred because, as another parent mentioned, "My son really liked it and worked through the book happily, without parental reminders." This opinion was also expressed in the children's comments such as that of the child who said, "I would like to do a book like this one every summer." Moreover, 80 per cent of the activities were carried out successfully.

When comparing results, we have found that there were no significant differences between the results obtained by state and private school pupils or between second and third cycle pupils. However, girls did significantly better than boys.

\section{Acknowledgements}

We would like to thank all the parents and teachers who have devoted part of their free time to answer the questionnaires, and also all the pupils who, besides answering the questionnaires, also lent us their holiday books.

\section{REFERENCES}

Alabau, I. (coord.) (2002). Evaluación de la Enseñanza y el Aprendizaje de la Lengua Inglesa. Madrid: Ministerio de Educación, Cultura y Deporte. 
Bazo, P., Peñate, M., Vera, S. and Gómez, M. D. (2003). Evaluación de la Anticipación del Inglés al Primer Ciclo de la Educación Primaria. Sta. Cruz de Tenerife: ICEC.

Breen, M. P. and Mann, S. J. (1997). "Shooting arrows at the sun: perspectives on a pedagogy for autonomy" in Benson and Voller (eds.).

Benson, P. and P. Voller. (1997). Autonomy and Independence in Language Learning. Addison Wesley Longman.

Cohen, A. (1995). "The role of foreign language thought in foreign language learning", in Working Papers in Education 11: 1-23.

Cohen, A. (1998). Strategies in learning and using a second language. Longman.

Holec, H. (1981). Autonomy and foreign language learning. Pergamon Press.

Jones, F.R. (1993). "Beyond the fringe: a framework for assessing teach-yourself-materials for $a b$ initio English-speaking learners", in System 21/4: 453-459.

Jones, F.R. (1998). "Self-instruction and success: A learner-profile study", in Applied Linguistics 19/3: 378-406.

Little, D. (1991). Learner Autonomy 1: Definitions Issues, Problems. Authentik.

Little, D., Dam, L. and Timmer, J. (2000). Focus on learning rather than teaching: why and how? Dublin: CLCS, Trinity college.

Madrid, D. (1999). La investigación de los factores motivacionales en el aula de idiomas. Granada: Grupo Editorial Universitario.

Oxford, R. (1990). Language Learning Strategies. Newbury House

Oxford, R. and Leaver, B.L. (1996). "A synthesis of strategy instruction for language learners" in Oxford (ed.).

Oxford, R. (1996). Language learning strategies around the world: cross-cultural perspectives. Technical Report 13. University of Hawaii.

Peñate, M. (coord.) (1998). Evaluación de la Enseñanza del Inglés. Educación Primaria. Las Palmas: ICEC.

Tarone, E. and Yule, G. (1989). Focus on the Language Learner. Oxford: Oxford University Press.

Vera, J. L. (2000). "Developing autonomy in a pre-service teacher training programme: a case study" in Little, Dam and Timmer (eds).

Vez, J.M. and Martínez, E. (2002). Competencia Comunicativa Oral en Lenguas Extranjeras. Santiago de Compostela: ICE.

Wenden, A. (2002). "Learner Development in Language Learning", in Applied Linguistics 23/1: $32-55$. 